Open Access

\title{
Constructing Legitimacy: How Do Chinese NGOs Become Legitimate Participants in Environmental Governance? The Case of Environmental Protection Law Revision
}

Hong Lin (1)

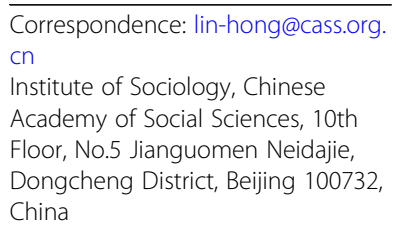

$\overline{\text { Correspondence: lin-hong@cass.org. }}$ $\mathrm{cn}$

Institute of Sociology, Chinese Academy of Social Sciences, 10th Floor, No.5 Jianguomen Neidajie, Dongcheng District, Beijing 100732, China

\begin{abstract}
Elaborating on the analytical framework of governance, this paper discusses three aspects of governance including the approach of how NGOs achieve subject legitimacy in environmental-governance participation, the legalization of participatory approaches, and the effectiveness of participatory result. The author takes the revision process of the Chinese Environmental Protection Law as a case study for thick description. It shows that 'practice of self-identification' is an effective approach for NGOs to construct subject legitimacy as they participate in environmental or even national governance, and the practice field with participation of multi acting subjects has already been and will continue to be a space to test for 'good governance' in China.
\end{abstract}

Keywords: NGO, Policy Advocacy, Environmental Governance, Legitimacy, Approach

The concept of 'governance' was introduced in China, shortly after its widespread adoption in the world during the 1990s. ${ }^{1}$ During the Third Plenary Session of the $18^{\text {th }}$ Central Committee of the Communist Party of China, modernizing the national governance system and governance capacity has been the central goal of deepening reform, as described in the document 'Decision of the CCCPC on Some Major Issues Concerning Comprehensively Deepening the Reform'. ${ }^{2}$ In contemporary academic circles, it has been widely acknowledged that governance implies multi-cohabitation, which means that subjects from sectors including government, market and society play different roles to form the national governance structure. NGOs, as one of the players in plural governance, are an intermediary for public participation. However, how NGOs in China construct their legitimacy in governance participation has not been adequately discussed either in the literatures of national governance or NGO studies. Regarding NGOs' participation in governance, policy advocacy is a high-level form of participation (Diamond, 1999:221). ${ }^{3}$ Meanwhile, for NGOs, policy advocacy could enhance their participation level and as well their legitimacy as a governance participant. Therefore, this paper will focus on NGOs' policy advocacy practices and elaborate on the revision process of the Chinese Environmental Protection Law, which is an illustrative case to demonstrate how Chinese NGOs construct legitimacy in governance participation.

(c) The Author(s). 2018 Open Access This article is distributed under the terms of the Creative Commons Attribution 4.0 International License (http://creativecommons.org/licenses/by/4.0/), which permits unrestricted use, distribution, and reproduction in any medium, provided you give appropriate credit to the original author(s) and the source, provide a link to the Creative Commons license, and indicate if changes were made. 


\section{Current studies on Chinese NGOs' participation in environmental governance and policy advocacy}

There have been plenty of studies on 'governance'. Internationally, the discussion has already entered a stage of reflection, such as Rothstein and Teorell's (2008) studies on the qualities of governance (Wilson, 2008; Longo, 2008), or Fukuyama's (2013) proposals on evaluation methods of governance quality (namely, procedures, inputs, outputs and bureaucratic autonomy), or Hysing's (2009) reflections on the changing roles of state from management to governance based on the case of Swedish forestry and transformation governance. Yu introduced the concepts of 'governance' and 'good governance' to China in his books Governance and Good Governance (2000) and Rights Politics and Public Politics - Contemporary Western Political Philosophy (2000).

While the international studies on governance have become increasingly technical and concrete, relevant research in China remains at a macroscopic level. According to Ding (2014), plural governance has existed in China to some extent. Since the 18th CPC Central Committee, the central government has repeatedly stressed the significance of establishing a multi-level social management system, consisting of party leadership, government accountability, society coordination, public participation and rule of law. Bao (2014), from the corporate governance perspective, argues that national governance can be divided into shared national governance and profit-split national governance. Zheng and Meng (2014) suggests that, to implement democratic governance, it is necessary to open policy making and enforcement to the public, so as to provide a suitable legal, policy and institutional environment for plural governance. In addition, some master's and doctoral dissertations have also discussed NGOs' influence from the perspectives of conflict management and environmental governance. ${ }^{4}$

Regarding NGOs' participation in national governance, existing studies tend to emphasize the particularities of the Chinese context. Jia (2007) depicted three models of civil participation with NGOs as intermediaries in China, and of these, institutional participation is the most empowering model. However, currently most Chinese NGOs are weak in self-organization and tend to participate in governance as individual organizations. While the decision-making participation model is quite common, advocacy NGOs have not constructed a universal and institutional path for participation, despite their occasional successes. In comparison with previous two models, the participatory governance model appears to be more promising and popular among rural and urban communities, vulnerable groups and also beneficiary groups of government-purchased public service. After evaluating Chinese environmental NGOs' activities, Tang and Zhan (2008) pointed out that most projects in this area tend to be 'un-political' and only a small number of environmental NGOs had limited involvement in 'political activities', such as supporting pollution victims or challenging local corporations. Also, based on two rounds of survey conducted with 28 Chinese environment NGOs, Zhan and Tang (2013) concluded that while the change to the existing Chinese political structure provided more opportunities for policy advocacy, seldom have environmental NGOs in China participated in policy advocacy or large-scale social movement. Unlike Western NGOs, environmental NGOs in China have very limited organizational capabilities and show little interest in public policy. While Jia's study clarified participation models, the two studies by Tang and Zhan illustrate the current situation of Chinese environmental NGOs' participation in governance, suggesting that Chinese environmental NGOs are still in an early developmental stage (Lin, 2016a). 
More studies of NGO participation in national governance have emerged since 2006. Wang (2006) classified Chinese public policy agenda setting into six models. According to this classification, 'people participation level' is the horizontal axis, and 'people' is one category on the vertical axis. Wu and Wang (2011) used John W. Kington's multi-source analytical framework to analyze Chinese environmental NGO participation in policy agenda setting, focusing on 4 dimensions: 3 sources (problem, policy, politics) plus policy windows. Song (2009) proposed that public participation in local legislation should be promoted from three aspects: improving the disclosure of legislative information, strengthening legislative hearings and establishing public polls regarding legislation. From the perspective of Ostrom's collective action theory, Dai (2013) pointed out that there were no public rational choice and social capital in public participation regarding Chinese legislation. Tianyi, Zongyu, and Xingui (2013) specifically discussed public participation in the making of environmental laws, arguing that the processes appear to be closed and are mainly government-directed. In addition, other research studied public or NGO participation from the perspective of the relationships between government and public (Wang, 2009; Xun, 2008; Yang and Cong, 2010; Aibao and Chen, 2007). It can be observed from these studies that Chinese NGOs enjoy limited opportunities for broader and higher-level activities (Kang and Han, 2006; Fan, 2010), and Chinese NGOs are trying hard to fight for action space in practice (Lin, 2016b).

In general, plenty of studies have analyzed Chinese NGO participation in national governance and policy advocacy, and many of these discussions take a macroscopic and categorization approach. However, three important issues stand out. First, either on national governance or environmental governance, the existing studies have not effectively dealt with the issue of NGO identity. That is, these studies either ignored the issue or simply considered NGOs as a part of the 'public'. On this point, the concept of 'public participation' is unclear both practically and theoretically. In this paper, NGOs are seen as a type of independent participant in plural governance. Second, the existing studies mainly focused on two aspects of participation, specifically, the current situation and the paths. Nevertheless, the governance analysis has been ignored. This article intends to fill this gap. Third, there are inadequate case studies in the area. While the macroscopic analyses are illuminating, the arguments cannot be strong without a concrete case. Therefore, this paper will thoroughly discuss one case based on long-term fieldwork and then engage with the theoretical framework of governance.

\section{Governance: the process of multiple subjects' interaction}

To explore the question within the framework of governance analysis, it is necessary to firstly clarify: what is governance? The article will use the widely accepted definition proposed by the Commission on Global Governance of the UN in Our Global Neighborhood (1995).

'Governance is the sum of the many ways individuals and institutions, public and private, manage their common affairs. It is a continuing process through which conflicting or diverse interests may be accommodated and co-operative action may be taken. It includes formal institutions and regimes empowered to enforce compliance, as well as informal arrangements that people and institutions either have agreed to or perceive to be in their interest. ${ }^{5}$ 
This definition clarifies several points. First, governance is a process. Second, the process includes plural subjects. Third, the participation institutions can be formal or informal. Fourth, the aim of this process is for plural parties to manage public affairs together.

Regarding the evaluation of governance, based on the internationally accepted Global Governance Indicators System (WGI), Rostan (2008) believes that impartiality should be the key indicator. Meanwhile, Fukuyama (2013) proposed another measurement method (procedures, inputs, outputs and bureaucratic autonomy) and stressed the significance of inputs (such as capacities, professionalism) and bureaucratic autonomy. Considering the Chinese context, this article will evaluate the quality of governance with Yu's (2000) six elements of good governance, namely, legitimacy, transparency, accountability, rule of law, responsiveness and effectiveness. The key ideas are three: legitimacy, rule of law and effectiveness. The three concepts respectively imply subjects, ways and results of governance. This is also similar to Ding's (2014) viewpoint ${ }^{6}$ on the elements of national governance.

In political science, the bases of legitimacy are consensus and identity, implying authority and order. That is, legitimacy is based on being the authority and respecting order. The former stresses identity while the latter refers to behavior. To achieve good governance, management bodies and personals are expected to maximize coordination among citizens as well as between government and citizens, and their legitimacy of public management comes from the maximum consent and approval of citizens ( $\mathrm{Yu}$, 2000: 117). Specifically, the concept of 'citizen' includes society and market. This implies that there are in total three subjects of governance, namely society, market and government. The legitimacy of these three subjects' qualification (the origin of this type of legitimacy will not be discussed in this paper) can be constructed during participation processes. Also, order-based legitimacy can be established during participation. Therefore, essentially, the legitimacy of governance infers process-oriented explorations rather than conclusive judgments.

Regarding governance methods, the direct goals of 'rule of law' are to regulate citizens' behaviors, to manage social affairs, and finally to maintain normal social orders (Yu, 2000: 118). Here, the term 'citizen' is interpreted at an individual level. It refers to individual legal subjects in the sectors of government, market and society. The so-called 'rule of law' in governance emphasizes that public participation should be process-oriented and actors must respect its principles, which refers to the legalization of the participation process. This does not only mean legal activities, but also refers to all behaviors that do not violate the written laws, that is, formal and informal institutionalized ways to participate in governance. As plural governance and its path are still in development, 'rule of law' in governance should also be process-oriented.

The third element is the effectiveness of governance, which is based on the referencing standards of governance goals and costs. The results of governance are not evaluated in a diachronic but in a synchronic manner. The line of the past, the present, and the future is the accumulation of different synchronic points. The effectiveness assessment should focus on the synchronic points, instead of the linear line. In other words, the evaluation includes two aspects: the effectiveness of each synchronic point and the effectiveness of the whole process. Therefore, governance effectiveness is essentially also process-oriented. 
In short, governance is a process and has three basic dimensions: authority-based legitimacy and order-based legitimacy; the principle of 'rule of law' in governance (including formal and informal institutionalized ways), and governance effectiveness at each synchronic point and through the whole process (with the reference to governance goals and costs). Next, this article will elaborate on the three basic dimensions, with the case of the Environmental Protection Law revision process.

\section{Amending the Environmental Protection Law: NGO Participation in Policy Advocacy}

Background of the Law Amendment

In 1989, China formally promulgated and implemented the Environmental Protection Law on the basis of the Environmental Protection Law (for Trial Implementation, 1979). In December 2010, the revision of the Environmental Protection Law was included in the legislative work plan (2011) of the Standing Committee of the National People's Congress. The amendment draft was passed in April 2014 and was formally implemented January $1,2015 .^{7}$ The question is, why did the NPC amend the law after 25 years?

First, awareness of environmental protection has been raised in China as a result of the emergence of various environmental problems.

The United Nations Conference on the Human Environment (Stockholm Conference, 1972) was enlightening for China regarding environment protection. High-level decision makers in China began to realize that there were serious environmental problems in the country, which required serious responses (Editorial Board of China Environmental Protection Administration 20 Years, 1994: 6). ${ }^{8}$ However, the ecological environment continued to deteriorate in China, since the 'Sixth Five-Year Plan' put forward 'putting efforts in controlling ecological deterioration' in 1981. The environmental issues happened in the West over hundreds of years of industrialization, yet broke out in China within only the past 20 years, with structural, complex and compressed characteristics (Xu, 2012: 2). On the one hand, the deteriorating ecological environment appears to constrain economic development. On the other hand, environmental problems also hinder social development and drag down people's life quality.

Next, the amendment was driven by the legislative system, particularly the gaps between slip laws and the basic law, and between environmental reality and the basic law. After the formal implementation of the Environmental Protection Law in 1989, the Standing Committee of the National People's Congress (NPC) has formulated and promulgated Marine Environmental Protection Law, Water Law, Grassland Law and Air Pollution Prevention Law. There have emerged increasingly obvious gaps between these slip laws and the basic law regarding legal ideas and regulations. For instance, the Environmental Protection Law (1989) failed to mention the principles of caution, risk prevention, and public participation, which have been embodied in other newly established and revised laws since 2002 (Zhang, 2013: 122).

As stated by Chunying Xin, the deputy director of the Law Committee in the Standing Committee of NPC in Law, 'China's environmental problems are not caused by the lack of rules. The problem is that our regulations are too outdated and impractical.' The Environmental Protection Law (1989) cannot effectively respond to the pressing 
problems of environmental pollution and ecological deterioration. Therefore, there had been 78 proposals for the revision of Environmental Protection Law (1989) on NPC ceremonies from 1995 to $2011 .^{10}$

The third motivation came from the administrative system of environmental protection. In 1974, the State Council set up a leading group to protect the environment, consisting of leaders from more than 20 ministries and commissions. There was also an office beneath the leading group, which was China's first environmental protection institution. In 1982, during institutional reform, the leading group was dismissed and the office was incorporated into the Ministry of Urban and Rural Construction and Environmental Protection and was renamed as the Bureau of Environment Protection (Zhang, 2013: 95). In 1984, the State Council set up the Environmental Protection Committee and the Bureau of Environment Protection was renamed as the State Bureau of Environmental Protection, which was the executive office for the State Council Environmental Protection Committee. In 1998, State Bureau of Environmental Protection was strengthened and the institution was changed into the Ministry of Environmental Protection in 2008. Environmental protection has gained more attention in the state, as shown by the continuous developments of the national environmental protection administrative institutions ( $\mathrm{Xu}, 2012$ : 8). However, descriptive institutional upgrade does not necessarily mean substantive power expansion. This gap became an internal driving force behind the legal amendment. As mentioned in 'the Amendment of the Environmental Protection Law of the People's Republic of China (draft), 'it is imperative to revise the existing Environmental Protection Law, which is to promote the law implementation and to hold the administrative offices accountable. The government should perform better in supervision and the legal liability must be strengthened.'

Fourth, the amendment was pressured by the public, which has become increasingly aware of environmental and ecological issues. In recent years, China's environmental accidents s have emerged quite frequently. For example, there were a total of 471 environmental accidents in 2014, of which 3 were major accidents, 16 were larger accidents and 452 were general accidents. ${ }^{11}$ Throughout the 20 years, China's public environmental awareness has gradually increased, which is rather different from the situation back to 1989 (Tianyi et al., 2013). The public are direct and indirect victims of environmental pollution. In light of local and regional environmental problems, the general public is motivated to fight for its rights by utilizing law and custom (Zhu, 2011), which produced societal pressure. Therefore, 'when the existing coordination mechanism on environmental conflicts cannot satisfy the needs of the people, and when the public's opinion cannot be expressed smoothly or their correct suggestions cannot be adopted, it is necessary to build a new set of public participation procedures, which are open and effective..' ${ }^{12}$

Due to the above factors, the Eleventh National People's Congress Standing Committee included the amendment of Environmental Protection Law into its five-year legislative planning. The internal and external pressures made the 'revision' possible, instead of only at the level of 'amendment'. During this process, plural participation was encouraged, which made the formerly closed legislation become more open. As a result, the process constructed more space for NGOs, which is the objective source of legitimacy for NGOs' participation in policy advocacy. 
Institutional space: two driving forces for NGOs to participate in policy advocacy

The amendment of the Environmental Protection Law was included in the legislative working plan (2011) of the Standing Committee of the National People's Congress in December 2010. Nearly four years later, Environmental Protection Law of the People's Republic of China (Drafted Revision) was passed in April 2014. The principle of the process was changed, as it started as 'amendment' and ended as 'revision'. ${ }^{13}$ Also, the participation of NGOs during the processes enriched the meaning of governance.

For a long time, China's environmental legislation has been led by the government, which makes the legislative process closed (Tianyi et al., 2013). However, during this revision, the process was open to plural subjects, particularly NGOs. This implied that 'society', as one of the three sectors, was no longer absent. There are two forces, namely top-down and bottom-up forces that constructed space for NGOs to institutionally participate in the revision.

First of all, how did the top-down force emerge, which demanded NGOs to participate in policy making?

When the revision process started, the NPC Committee of Environment and Resources had consulted relevant departments and experts several times. The Committee also visited Hunan, Hubei, Chongqing, Fujian, Jiangsu, Shaanxi provinces and other places to do research from April to September. A seminar was held in Xu Zhou city of Jiangsu province to discuss the revision, joined by committees of environment and resources from different provinces and cities, some NPC delegates who proposed the revision, and the Law Committee in NPC Standing Committee. Meanwhile, expert consultation meetings and departmental meetings were organized to analyze the issues of environmental protection planning, supervision, pollution charge and treatment with a time limit. During the process of drafting the amendment, the NPC Committee of Environment and Resources formally consulted 18 central institutions, such as the Law Committee in NPC Standing Committee and the Supreme People's Court, and gathered opinions from the 34 provinces, autonomous regions and municipalities. Further, the Committee listened to comments from representatives who had submitted four proposals during the Fifth Session of the NPC and other local people in Shanghai in March 2012. ${ }^{14}$ It can be seen that the internal process of the revision involved central and local governments, the NPC system, the judiciary system and other relevant institutions. The procedures included department consultation, expert advice, NPC research, field research and public consultation. Including these diverse participants implied diverse positions and disagreements. To be more specific, 'during this revision, some departments proposed to add more requests on the administrative system. Some put forward the sewage permit system, environmental pollution liability insurance, and environmental function zone. The current Environmental Protection Law did not adopt these proposals. Further, there are disagreements on these points among relevant departments in the State Council. ${ }^{\prime 15}$ Significantly, the difficulties in coping with the diverse opinions during the policy making process made it possible to introduce new players in the field. There were two public consultation sessions during this revision ${ }^{16}$, which occurred after the first and second reviews of the NPC Standing Committee. The debates at each stage of the revision were transparent and open to the public. Public feedback also influenced the legislation. This helped promote democracy in the legislation and also enhanced the legitimacy and justice of the legislation (Song and Zhou, 2007). 
Second, how did the bottom-up force emerge, which drove NGOs to participate in policy making?

As the basic law in the field of environmental protection, the Environmental Protection Law plays a decisive role in the construction of space for environmental NGOs. Participating in the legislative process has two meanings: one is to participate in the exact policy; another is to participate in politics. On the one hand, this is a matter of space for NGOs' actions. On the other hand, this is also a process by which NGOs can construct their own identity. In contemporary China, it is a challenge for NGOs to explore more space through participation in legislation, which is also an opportunity for them to construct their role and identity.

In the case of Friends of Nature, the director of the organization explained why they participated in the legal revision.

Friends of Nature has participated in policy advocacy since Mr. Liang's ${ }^{17}$ era till now. As far as I know, there are very few other NGOs in China who have continually and deeply advocated for legal changes. At the same time, we have established connections with NPC delegates and experts. There is also a Legal Advocacy Office in Friends of Nature. Overall, we interact with all relevant sectors. Regarding the advocacy on environmental public interest litigation, we had positive interactions with experts, media and members. We also expressed our voices through NPC delegates' proposals. Our coordination with other environmental NGOs and our own members are also important. We must do this, even if we fail. This is what we are supposed to do. During the process, NGOs gradually realized the significance of the participation. At the same time, those NGOs who took part in the process deserve extra points. (Interview number: FONZHBJ20150109BJ)

The above statement reveals several things. First, Friends of Nature considers policy advocacy as one of its organizational missions. Namely, 'this is what we are supposed to do'. Second, policy advocacy is a tradition of this organization, as 'Friends of Nature has participated in policy advocacy since Mr. Liang's era'. Third, Friends of Nature has capabilities in policy advocacy, which is, practical experience, legal professionals, and social relation network (including NPC delegates, experts, media, members, and NGOs). They also have evaluation and preparation of participation risks for the advocacy results. Fourth, Friends of Nature has social influence based on its reputation, which is both diachronic and synchronic. Together, the four factors created the motivational force for Friends of Nature to participate in the legal revision.

In fact, besides Friends of Nature, there were also other NGOs of similar type that participated in NGO-oriented advocacy, such as China Environmental Protection Federation, SEE Foundation, the University of Nature etc.. Similar to the state system, there are also diverse voices in NGOs communities, who are different in identity, cognition, attitudes, abilities, behavioural patterns and strategy choices. These differences can produce better coordination, but may also lead to conflicts and dissolutions.

\section{The process of action: NGO participation in environmental policy advocacy}

During the revision, features of plural governance were strongly reflected in two periods. The first occurred when the second draft was reviewed by the third meeting of 
the Standing Committee of the 12th National People's Congress (around June 26, 2013). The second was during the public consultation period of the second draft review (July 19-August 18, 2013).

In the draft sent for the second review, the subject of environmental public interest litigation is defined as: 'China Environmental Protection Association and the environmental protection association in provinces, autonomous regions and municipalities can bring a lawsuit to the people's court'. This article became the focus of attention of all social parties once it was announced.

In response to this situation, Friends of Nature launched an urgent appeal regarding the Environmental Protection Law Amendment (draft) on June 26, 2013, calling for an expansion on the subject of environmental public interest litigation. ${ }^{18}$ The arguments in the appeal mainly focused on legal principles and basic technical requirements for the legislation, potential conflicts between the legislation and the work of the judicial and administrative systems, contradictions between the limited litigation subjects and litigation practices, as well as legislative goals.

On August 13, 2013, at the end of the public consultation for the second review draft, Friends of Nature submitted the 'Opinions on the Second Review on the Amendment to Environmental Protection Law'19, and 'the Comparison Lists of Suggestions from Friends of Nature on the Revision of Environmental Protection Law'. The organization proposed six suggestions, that is, 'adding citizens' environmental rights in the law,' 'opinions on amending the provisions on public interest litigation, 'improving environment impact assessment system,' 'establishing solid waste recycling system,' 'establishing social supervision system', and 'building a unified platform for corporate information disclosure'. Regarding the subject of environmental public interest litigation, Friends of Nature put forward two types of subjects. One was the subject for 'stop loss' about claims for 'the stop of infringement, elimination of harm and danger'. The other one was the subject for 'relief', about claims concerned with 'repairing the environment and compensating the environmental damage'. The former refers to the relevant organizations (including NGOs) in the Civil Procedure Law, while the latter points to the environmental administrative institutions and other relevant agencies.

On the same day, another environmental NGO, the University of Nature, launched a joint signature letter, named 'an open letter to civil environmentalists in China: everyone has the right to initiate public interest litigation'. ${ }^{20}$ The joined signature letter was signed by 360 individuals and 112 organizations, and further submitted to the NPC Standing Committee during the second public consultation. As it was claimed in the open letter, 'everyone has the right to initiate environmental public interest litigation. Everyone can go to the court to learn the environmental disasters and to confront the perpetrators. Everyone can go to court to charge the environment polluter, making the ecological destroyers impossible to find tranquillity. Everyone can participate in the struggle of environment protection through the law, pressuring the government to improve its governance capability and forcing the corporates to enhance their performances.' It claimed that 'it is a great insult to the public when our Environmental Protection Law defines 'public' narrowly as 'China Environmental Protection Federation'. This is a huge blow to the public environmental awareness, as there is only one small exit for all environmental enthusiasm of the public in the whole country'. It further suggested that the clause on the subjects of environmental public interest litigation 
should be revised as in the face of the activities polluting environment and damaging public interests, every citizen of the People's Republic of China, every natural and legal person of the People's Republic of China, can go to the people's court. The court must accept the suit timely and guarantee the justice in the trail.'

Key persons of the two organizations also expressed their opinions in different ways about the participation process. The director of the Law \& Policy Advocacy Department in Friends of Nature introduced,

'We launched an urgent advice letter on the internet and gave the materials to media, which created a high level of media exposure. We also joined the seminars on the second draft organized by scholars, on which we expressed our position.

Meanwhile, we also visited NPC delegates and asked them to support and spread our views. After the public consultation of the second draft, we used different methods, such as micro-interviews on Sina and drafting amendment comments together with different groups, which were sent to the Law Committee of the NPC's Standing Committee. (Interview number: FONGF20150108BJ).'

On participation, the head of the University of Nature said,

'We tried joint signature for four times, starting from June 2013. We argued that everyone has the right to bring public interest litigation to the court. On that morning, we published the joint signature on our own website and other platforms. Soon, more than a hundred organizations responded to us. I did this as I just think it is a must. When you do a thing, you do not necessarily need to be correct, as there are multiple standards of being correct. But you must have your own clear style (Interview number: NUFYF20150113BJ).'

From the urgent appeals and letters of advice, open letters with joined signatures and interviews of key persons, one can observe that the two NGOs obviously had quite different styles, which made it possible to supplement each other and lead the advocacy to a more productive result. However, when the differences were too large to compromise, there emerged the risk of dissolution. As the director of Friends of Nature analyzed,

'Many of NGOs tend to blame the China Environmental Protection Association, due to its official background. In fact, they have contributed a lot in environmental public interest litigations for a long time. But they cannot win the trust of grassroots organizations. Of course, it is understandable, as the Government-organized NGOs enjoy too many privileged resources, which would annoy grassroots NGOs.

However, at this critical time, blindly attacking China Environmental Protection Association was unwise, as it could lead to the dissolution of social groups. It was not a strategy, but simply a vent of emotion.' (Interview number: FONZHBJ20150109BJ)

Follow-up: the possibilities of NGOs participating in the construction of a practice field The new Environmental Protection Law was formally implemented on January 1, 2015. Later, the Supreme Court issued the 'Supreme People's Court's Interpretation on 
Several Issues Concerning the Applied Laws on the Trial of Environmental Civil Public Interest Litigation Cases', which was implemented on January 7, 2015. Unlike the revision of the Environmental Protection Law, only a few NGOs participated in the formulation process of the Supreme People's Court's Interpretation. Friends of Nature extended its policy advocacy to the stage of judicial interpretation. The director explained,'As a legal advocacy, its purpose is to make more space within the law, for the benefit of the public. After the promulgation, the space for action was still not clear. We must keep pushing. Finally, it showed that it is significant and might be more effective to follow the advocacy result'. ${ }^{21}$

At this stage, public consultation was still the most important channel for Friends of Nature to participate in the judicial interpretation. On October 1, 2014, the Supreme Court issued the 'Interpretation on Several Issues Concerning the Applied Law on the Trial of Environmental Civil Public Interest Litigation Cases (draft for soliciting opinions)', which was open to advice and comments from the public within one month. The document was formally passed on December 8, 2014. During the period of public opinion solicitation, Friends of Nature jointly organized a seminar, attended by the environmental organizations qualified to be the plaintiffs in public interest litigation cases, scholars and environmental public interest lawyers. Together, they produced 'Suggestions on the Judicial Interpretation' and submitted it to the Supreme Court in the form of joint signature on October 30, 2014. ${ }^{22}$ Eleven organizations and five individuals signed it. ${ }^{23}$ Afterward, Friends of Nature continued their advocacy through informal institutional approaches, such as seminars and personal contacts etc..

Besides the opportunity for public opinion solicitation, Friends of Nature also made other advocacy attempts, as stated by the director of the Law\& Policy Advocacy Department in Friends of Nature.

'On our seminars, we wrote advice letter on the judicial interpretation together with lawyers and experts and then sent it to the Supreme People's Court. We also communicated with the Supreme Court and got feedbacks. People from the Supreme Court attended our seminar in Wuhan. On that meeting, the Supreme Judge presented the latest draft of the judicial interpretation, and we also told them the advices from Friends of Nature, some of which were taken on the spot. Plus, we managed to communicate with the Supreme Court on our seminar in Tianjin. Specifically, we focused on the exemption clause on the burden of proof and argued that it is very unfavourable for the plaintiff to provide the proof. In response, the judge from the Supreme Court said that there were disagreements within the court on this point and they were planning to delete this clause. Knowing this, we stopped mentioning this point and shifted to other points related to us. Most advices in our letter to the Supreme Court were taken, which involved 3-4 clauses in total. There is one point worth mentioning. On the seminar in Tianjin, one person from the Supreme Court reminded me that, we should also mention those clauses that we support. Otherwise, they might be deleted. This is very important. On some controversial clauses, we also expressed our supportive views clearly. The Supreme Court spoke highly of our letter. On the press conference (January 6, 2015) of the Supreme Court, our case of Nanping in Fujian province was mentioned twice as an example to explain the subject of cross-regional litigation. Obviously, we are entitled to be the joint plaintiff of this case.' (Interview number: FONGF20150108BJ) 
The role and identity of NGOs have changed largely during this legal review, as shown by the facts that environmental institutions took civil society into consideration and that the Supreme Court sought public support in the formulation of judicial interpretation.

It is still too early to discuss qualitative change. Yet NGOs started to participate in higher level political activities and to construct NGOs' participation legitimacy during the process. This is a breakthrough in comparison to the leader-oriented participation in policy and low level political involvement of the past.

However, during this process, different subjects have quite different self-evaluations and expectations of others. In the eyes of environmental protection administrative departments, the environmental public interest litigation should only include civil litigation, while the administrative litigation should be excluded. On the contrary, both the judicial system and NGOs insisted that both types of litigation should be included and promoted. In the future, different parties will have more interactions in the forms of coordination and competition. ${ }^{24}$ This process will become a practice field for 'good governance'.

\section{The construction path of NGOs' legitimacy as a subject of environmental governance}

The above section analyzed the backgrounds, process and follow-ups of the revision of Environmental Protection Law. This part will discuss how NGOs construct their subject legitimacy in participating in governance, with the framework of the three basic dimensions of governance. In the process of revision, NGOs' subject legitimacy was constructed from two paths, that is, government's intentions to introduce external opinions and NGOs' own motivations in policy advocacy.

The Chinese government showed openness and tolerance to NGOs' policy advocacy. Whether it is still only 'administrative adoption', the government appeared to be more open and humble. Especially in the formulation process of judicial interpretation, it is obvious that the government has acknowledged NGOs' independent position, as shown from NGOs' advocacy techniques and results. It also can be seen from the fact that the Supreme Court took Friends of Nature as an example to illustrate the feasibilities of cross-province environmental public interest litigation. Some studies pointed out that 'Environmental NGOs can build an institutional communication and coordination mechanisms with NPC delegates, CPPCC members, officials in relevant fields, as well as experts and scholars' (Wu and Wang, 2011). In addition, this article believes that such 'policy advocacy capabilities' will help NGOs become one of the authorities and therefore gain legitimacy. This view may be over-positive, yet the legal revision has shown such possibility. From 'being oriented' to 'equal cooperation'25, this process implied NGOs are on their way to becoming authorities.

Meanwhile, NGOs' motivation during policy advocacy is also a source of its self-given authority. Despite the fact that NGOs only participated in the legal revision, the effects of their actions, their professionalism and their capabilities of social resource mobilization and integration have already made them entitled to be one of the parties in governance. This empowerment was not only reflected in the process of amendment, but also in the revision results. 
First, since the era of Liang, Friends of Nature set up a legal and policy advocacy team in 2005, and finished the transition from 'charismatic leader' to 'professional organization' in 2008 (Wang and $\mathrm{Xu}, 2004$ ). Since the launch of 'the first civil litigation case of environmental public interest in China' in September 2011, Friends of Nature began to accumulate judicial practice experience. Only with a professional team and judicial practice experience could Friends of Nature play an important in this revision. These are also necessary conditions for this NGO to build its authority as a governance participant.

Second, Friends of Nature efficiently integrated all approaches and resources during the advocacy, through either formal or informal institutionalized channels, which is pioneering work among NGOs in China. Being the subject of authority was not the only NGOs' achievement in this advocacy. Also, the principle of 'rule of law' empowered them with legitimacy in either formal or informal institutionalized participation. Multiple advocacy channels imply diverse social resources. During the two decades, Friends of Nature has established its marvellous social reputation, broad networks and various resources (including funding, media, experts, members, NPC delegates, NGO partners, etc.), which were fairly helpful during the advocacy. Zhou (2006) summarized 12 approaches of NGOs participating in policy advocacy. In this attempt, all approaches, except 'protest', were utilized in varying degrees. ${ }^{26}$

Third, the effectiveness of the advocacy also enhanced the legitimacy of NGOs as governance participants. This was shown directly from the new chapter on 'information disclosure and public participation' in the revised Environmental Protection Law and the adoption of NGOs' advices in the judicial interpretation. Of course, this was owing to both the increased policy influence of NGOs and the change of governments' attitudes in policy makings. As Xun (2008) puts it, a few government departments with strong ecological awareness or environmental commitment are becoming the supporting force for NGOs within the government system. They are providing NGOs with a better 'political opportunity structure'. Friends of Nature, as one of the most influential Chinese NGOs domestically and internationally, naturally has become the biggest beneficiary.

The above discussion described and analyzed the path of Chinese NGOs in constructing their subject legitimacy as governance participants. During the revision of Environmental Protection Law and the formulation of its judicial interpretation, there were multiple parties participating in both processes of policy making and policy advocacy with diverse discourses, and reached a consensus result at the end. These are the basis of order legitimacy, which provides behavior norms for the implementation of the new Environmental Protection Law and its judicial interpretation. From this process, one can see the possibility of building an order together with multiple participating parties, and this may firstly happen in the implementation of policy and law. It is foreseeable that there will be more diverse and professional NGOs participating in policy advocacy in the future. The development of NGOs in various areas will constantly improve public participation and speed up the institutional construction of pluralistic governance. Different types of NGOs, as intermediaries, will play a bigger role in representing different groups of the public. Thus, NGOs and other political forces will interact with and monitor each other, establishing a new political structure of 'checks and balances' (Wang, 2009). The possibilities of this scenario have been observed in the process of this legal revision. 


\section{Conclusion: the construction of subject legitimacy based on practice}

There are three basic aspects of governance, including governance oriented to the goal of good governance: authority-based and order-based legitimacy; the principle of 'rule of law' in governance (including formal and informal institutionalized ways), and governance effectiveness at each synchronic point and through the whole diachronic process (with reference to governance goals and costs). The three dimensions have been endowed with practicality due to the practice process of multi-party interactions. This is mainly reflected in the following three aspects:

First, legitimacy, rule of law, and effectiveness are mutually transformative in practice. In this legal revision, to some extent, 'NGOs' advocacy realized the function of being empowered by the citizens' (Jia, 2007). According to some studies, even though institutionalized conversation channels between NGOs and governments have emerged, it does not mean that NGO's actions are empowered by citizens (Jia, 2007). Considering the intense and effective participation by NGOs in this revision, this paper believes that institutionalized participation paths include both formal and informal as well as direct and indirect approaches (Wu and Wang, 2011), which may become real paths for NGOs to be empowered by citizens. The 'rule of law' principle and 'effectiveness' of NGOs' participation may strengthen NGOs' legitimate position, once institutionalized participation channels are gradually expanded and improved.

Second, the practice of self-identification (自证式实践) is an effective way to construct NGOs' subject legitimacy as one of the participants in governance. For NGOs, when the legal arrangements are outdated, their space of action is expanded both by the empowerment of formal institutions and informal institutionalized practices. During this revision, Friends of Nature's subject legitimacy was self-identified by its judicial practice in the case of 'Yunnan Qujing Chrome Slag Pollution'. Based on this, this NGO pushed the expansion of subjects qualified to participate in environmental civil public interest litigation. Also, the Supreme Court confirmed the NGOs' legitimacy as potential plaintiffs in cross-province environmental civil public interest litigation by taking the case of 'Fujian Nanping Ecological Damage' as an example, in which Friends of Nature and Fujian Green Homelands were plaintiffs. The civil society's attempts at driving legal revisions have the same logic as 'pilot' and 'innovation', which is to improve the lagged laws and also make it possible for NGOs to construct their subject legitimacy as participants in national governance.

Third, there also emerged the practice field based on the interaction process of multiple parties. In the process of this revision, NGOs, environmental departments in governments and judicial departments transformed their experience into legal language to advocate for a new environmental public interest litigation system. While we cannot quantify the influence of NGOs in the process, such participation is of great significance in itself. Due to the newly added chapter of 'information disclosure and public participation' in the new Environmental Protection Law, the 'society', who had been ignored or suppressed previously, formally gained subject legitimacy. To some extent, this empowerment on the qualification of subjects surely changed the practical structure and constructed a new practice field. The practice field will be constructed together by multiple players who have competition and coordination relationships. This is different from the type of advocacy dominated by one particular party, but is instead a process jointly participated by various actors. The subjects in the field still retain their 
main characteristics, yet they could be aware of the diversities in the field and seek coordination during the interactions. This will add new meanings to the field, such as equal positions, more democratic behavioural norms, and more effective interaction mechanisms. Although the results depend on whether the interactions are zero-sum games or non-zero-sum games, this article tends to be positive given the process of this legal revision. This practice field with diverse subjects will become or may have already become a valuable testing experiment field for the construction of good governance in China.

Governance, as a multi-agent interaction process, has been given practicality as mentioned above. In the course of practice, NGOs respected 'rule of law' in formal and informal institutionalized participation and gained effective results. This provided possibility for NGOs to construct their subject legitimacy as participants in plural governance.

\section{Endnotes}

${ }^{1}$ The World Bank used the term "governance crisis" for the first time in its 1989 report to describe the social situation in Africa. In 1992, the World Bank published an annual report entitled "Governance and Development." In the same year, with great supports and commitments from the United Nations Secretary-General Boutros Boutros-Ghali, the Commission on Global Governance was established, and then in 1995, "Our Global Neighborhood: Report of the Commission on Global Governance" was published, which defined the concept of "governance." Subsequently, the commission started to publish the magazine Global Governance. With the development of the "governance" concept, international institutions represented by the World Bank have developed a variety of analytical tools for governance assessment, such as the World Governance Index (WGI), the Governance Analysis Framework (GAF), etc.

${ }^{2}$ In 2014, the general secretary of CPC Jinping Xi pointed out that "the national governance system and governance capability are the central reflection of state's institutions and its ability of implementation. National governance system is led by the Party, which includes the institutional and legal arrangements in the areas of economics, politics, culture, society, ecological civilization and party building, etc.; it is a set of closely linked and coordinated national system. National governance capability refers to the ability to use the national system to manage various social affairs, including the aspects of reform and stable development, civil affairs, diplomacy, defense, the managements of the party, military and state, etc. National governance system and governance capability are an organic whole. Only with good national governance system, can the governance capability be effectively improved, and only with great governance capability, can the national governance system fulfill its missions."

${ }^{3}$ Diamond summarizes six types of NGO activities: (1) express interest, concern, and ideas; (2) exchange information; (3) achieve goals based on consensus; (4) appeal to the nation; (5) promote improvements to state structure and function; and (6) hold state officers accountable. According to him, the level of NGOs' activities increases following this sequence (1-6). The higher the level, the larger the influence on civil society and the construction of democracy.

${ }^{4}$ Boyan's (2012) dissertation argues that social organizations can take on two different roles in society governance conflicts, namely third party defense and neutral third 
party, and analyzes the internal and external conditions that promote or constrain NGOs from playing these roles. Zheng's (2014) thesis, taking Green Cross in Xiamen as a case, discusses three factors affecting the relationships between governments and NGOs, namely the ecology of environment politics, governmental regulations for NGOs, and the developmental stage of grassroots organizations.

${ }^{5}$ The Commission on Global Governance, 1995, Our Global Neighborhood: Report of the Commission on Global Governance, Oxford: Oxford University Press.

${ }^{6}$ Ding (2014) suggested that any type of national governance is a comprehensive system, including the subjects and objects of governance, governance goals, and method. Among these elements, the subjects of national governance refer to the actors, which could be individuals or groups and organizations. The object of national governance refers to public affairs in the areas of politics, economics, and culture. The goal of national governance is to meet the expectations of national governance, while the methods refer to various approaches and ways, such as national institutions, laws, and policies. The national governance system stresses the specific intrinsic logic among the elements.

${ }^{7} \mathrm{NPC}$ Committee of Environment and Resources initiated the amendment process for the Environmental Protection Law in January of 2011, led by Haiqing Pu, according to: China NPC Committee of Environment and Resources, 2012, "The Explanation on People's Republic of China Environmental Protection Law Amendment (draft)", available at the website of China NPC: http://www.npc.gov.cn/huiyi/lfzt/hjbhfxzaca/ 2012-08/31/content_1735795.htm.

${ }^{8}$ Influenced by the United Nations Conference on the Human Environment (Stockholm Conference, 1972), China held its first national environmental protection conference on August 5-20, 1973, directly led by Enlai Zhou. In November of the same year, the State Planning Commission, the State Construction Committee, and the Ministry of Health jointly approved and promulgated China's first set of environmental standards, known as "The Pilot Emission Standards on the Industrial Three Wastes."

${ }^{9}$ Bo Peng and Lei Mao, 2014, "The first revision on Environmental Protection Law in 25 years," available at the website of China NPC: http://www.npc.gov.cn/huiyi/lfzt/ hjbhfxzaca/2014-04/25/content_1861322.htm.

${ }^{10}$ China NPC Committee of Environment and Resources, 2012, "The Explanation on People's Republic of China Environmental Protection Law Amendment (draft)", available at the website of China NPC: http://www.npc.gov.cn/huiyi/lfzt/hjbhfxzaca/ 2012-08/31/content_1735795.htm.

${ }^{11}$ Sun, Xiuyan. 2015. "471 environmental emergency events last year," available at the People's Daily Online: http://env.people.com.cn/BIG5/n/2015/0126/c101026447044.html.

${ }^{12} \mathrm{Yu}$, Xiaojie, and Hao Hu. 2012. "China may amend the laws to guarantee the rights of the public to know and to participate in environment protection," available at the website of China NPC: http://www.npc.gov.cn/huiyi/cwh/1128/2012-08/31/ content_1735538.htm.

${ }^{13} \mathrm{Yu}$,Xiaojie, Ruizhen $\mathrm{Gu}$, and Jingjing Wu, 2014. "From amendment to revision: the Environmental Protection Law expressed people's opinion after four reviews," available at the website of China NPC: http://www.npc.gov.cn/huiyi/lfzt/hjbhfxzaca/ 2014-04/25/content_1861318.htm. 
${ }^{14}$ China NPC Committee of Environment and Resources. 2012. "The Explanation on People's Republic of China Environmental Protection Law Amendment (draft)", available at the website of China NPC: http://www.npc.gov.cn/huiyi/lfzt/hjbhfxzaca/ 2012-08/31/content_1735795.htm.

${ }^{15}$ China NPC Committee of Environment and Resources. 2012. "The Explanation on People's Republic of China Environmental Protection Law Amendment (draft)", available at the website of China NPC: http://www.npc.gov.cn/huiyi/lfzt/hjbhfxzaca/ 2012-08/31/content_1735795.htm.

${ }^{16}$ During the first public consultation period (August 31, 2012 to September 30, 2012), the Commission received 11,748 comments from 9572 people. During the second period (July 19, 2013 to August 18, 2013), 822 comments were received from 2434 people.

${ }^{17}$ Congjie Liang, one of four founders of the Friends of Nature, which started to implement activities in 1993, and officially registered in 1994.

${ }^{18}$ Friends of Nature, 2013, 'Emergent appeal on the clause of environmental public interest litigation in Environmental Protection Law Amendment (Draft), field materials, it can be referred to here: http://business.sohu.com/20130627/n379969680.shtml.

${ }^{19}$ Friends of Nature, 2013, "Opinions on the second review of the Environmental Protection Law (draft)," field materials.

${ }^{20}$ Source: field log, interview number: NUFYF20150113BJ.

${ }^{21}$ Source: field log, interview number: FONZHBJ20150109BJ.

${ }^{22}$ Friends of Nature, 2014, "Proposals on Judicial Interpretation of Environmental Civil Public Interest Litigation," field materials.

${ }^{23}$ The Supreme Court sent a letter of thanks to Friends of Nature on 22 January 2015 for their valuable comments and suggestions. At the same time, other participating institutions also received a letter from the Supreme People's Court, such as the China Environmental Protection Federation and Legal Assistance Centre for Pollution Victims, China University of Political Science and Law.

${ }^{24}$ In fact, China's NGOs have accumulated a wealth of experience in action advocacy. For example, the China Environmental Protection Federation has participated in 24 cases of environmental public interest litigation since 2009 and proposed to relevant departments at various times. The Pollution Victim Center in China University of Political Science, established in 1998, has always promoted the system of environmental public interest litigation which it has practiced in private litigation cases. In September 2011, Friends of Nature, along with Chongqing Green Volunteers Association, sued Yunnan Luliang Chemical Industry Co., Ltd. and Yunnan Luliang Peace Technology on Qujing City Intermediate People's Court. This became the first civil litigation case of environmental public interest in China. The practice attempt played a significant certifying role during the legal revision. Besides the three organizations above, other NGOs also participated in the promotion in different ways.

${ }^{25}$ Deng and Chunping (2006) argue that the evolution of the relationships between China's state and society will go through several stages: state cooperative system, proto-state cooperative system, and finally social cooperative system. The position of NGOs would also experience the periods of government domination, the corporation between government and society, and society autonomy. In accordance, the relationships between government and NGOs would change from absolute domination, to relative domination and finally to equal cooperation. 
${ }^{26}$ According to Zhou (2006), Chinese NGOs participate in public policy affairs in the following 12 ways: 1 . provide relevant information and policy recommendations; 2. provide private contacts; 3 . be direct representatives; 4 . provide administrative reconsideration and litigation; 5. participate in the hearing session; 6. organize academic seminars; 7. produce publications in the form of journals, magazines, newspapers; 8 . create a united lobby; 9 . organize joint action; 10. use mass media; 11 . use international power; 12. generate protests.

\section{Abbreviations}

CCCPC: Central Committee of the Communist Party of China; NGO: Non-governmental organization; NPC: National People's Congress; UN: United Nations

\section{Acknowledgments}

This article is based on the author's fieldwork in Friends of Nature, an environmental NGO in China (formal fieldwork is from December 2013 to December 2014, and follow-up is from January 2015 to May 2018). Except for special clarification, all materials used in this article come from the author's participant observation and interviews, which are used for informed consent. The fieldwork was mainly located in Friends of Nature but also included other active and representative environmental NGOs in China.

\section{Authors' contributions}

The author read and approved the final manuscript.

\section{Competing interests}

The authors declare that they have no competing interests.

\section{Publisher's Note}

Springer Nature remains neutral with regard to jurisdictional claims in published maps and institutional affiliations.

Received: 23 March 2018 Accepted: 1 May 2018

Published online: 15 May 2018

\section{References}

Aibao, Huang, and Wanming Chen. 2007. The interactive relationship between eco-government construction and ecological NGO development. Exploration 1: 57-61.

Bao, Gangsheng. 2014. State governance and the empirical study on political science. Academic Monthly 7: 5-8.

Boyan, Zhao. 2012. The role of NGOs in the management of public conflict. Nankai University doctorate thesis.

China Environmental Protection Administration 20 years' editorial board. 1994. China environmental protection administration 20 years. Beijing: China Environmental Science Press.

Dai, Shuiping. 2013. Dealing with the difficulties of public participation-the perspective of Eleanor Ostrom's collective action theory. Journal of Northwest University (Philosophy and Social Science) 1: 49-52.

Deng, Weizhi, and Lu. Chunping. 2006. Cooperative Model of NGO Development. Nanjing Social Science 11: 126-130.

Diamond, L. 1999. Developing democracy: toward consolidation. Baltimore, MD: Johns Hopkins University Press.

Ding, Zhigang. 2014. How to understand the state governance and state governance system. Academic Circle 189: 65-72.

Fan, Minglin. 2010. The interactive relationships between NGOs and government-a comparative case study on corporatism and civil society. Sociological Studies 3: 159-176.

Fukuyama, Francis. 2013. What is governance? Governance: An International Journal of Policy, Administration, and Institution 26 (3): 347-368.

Hysing, Erik. 2009. From government to governance? A comparison of environmental governing in Swedish forestry and transport. Governance: An International Journal of Policy, Administration, and Institution 22 (4): 647-672.

Jia, Xijin. 2007. An analysis of NGO avenues for civil participation in China. Social Sciences in China (Summer): 137-146.

Kang, Xiaoguang, and Heng Han. 2006. The classification of control: current research on the relationship between state and society in mainland China. Sociological Studies 6: 73-89.

Lin, Hong. 2016a. The diachronic and synchronic dimensions of the development of Chinese environmental NGOs. Chinese Environment (8): 40-43.

Lin, Hong. 2016b. National policy and social action: the possibility of practice boundary between state and society. Journal of Xinjiang Normal University 1: 112-122.

Longo, Francisco. 2008. Quality of governance: impartiality is not enough. Governance: An International Journal of Policy, Administration, and Institution 21 (2): 191-196.

Rothstein, Bo, and Jan Teorell. 2008. What is quality of government? A theory of impartial government institution. Governance: An International Journal of Policy, Administration, and Institution 21 (2): 165-190.

Song, Fangqing. 2009. The difficulties and solutions of public participation in local legislation. Law 12: 28-31.

Song, Fangqing, and Gangzhi Zhou. 2007. On the procedural construction of legislative fairness. Journal of Xiamen University: Philosophy and Social Science 1: 55-62.

Tang, Shuiyan, and Xueyong Zhan. 2008. Civic environmental NGOs, civil society and democratisation in China. Journal of Development Studies 44 (3): 425-448. 
Tianyi, Yang, Song Zongyu, and Xu Xingui. 2013. On the ecological crisis, the perspective of public participation in environmental legislation. Eco-economy 2: 161-164.

Wang, Ming. 2009. Towards civil society - the history and trend of the development of NGOs in China. Journal of Social Sciences of Jilin University 3: 5-12.

Wang, Ming, and Yushan Xu. 2004. Chinese social organizations: the 2003 phenomenon. Academia Bimestris 4: 39-42. Wang, Shaoguang. 2006. China's public policy agenda setting models. China Social Science 5: 86-99.

Wilson, Granham. 2008. The quality of government. Governance: An International Journal of Policy, Administration, and Institution 21 (2): 197-200

Wu, Xiangling, and Zhihua Wang. 2011. The mechanisms of China's environmental NGOs' in participating in policy agenda setting, with the multi-source analysis framework. Journal of Central South University (Social Science Edition) 5: 29-34.

Xi, Jinping. 2014. The idea of re-unifying the party to the spirit of the third plenary session of the eighteenth party. People's Daily 1: the second column.

Xu, Huaqing, and Guo Yuan. 2012. The environmental constraints of China's energy development. Beijing: China Environmental Science Press.

Xun, Qingzhi. 2008. The relationship between environmental non-governmental organizations and the government: the case of friends of nature. Jianghai Journal 2: 130-136.

Yang, Xiaoguang, and Yufei Cong. 2010. The coordination between grassroots NGOs and government under the low carbon economy. Contemporary Economic Research 11: 52-55.

Yu, Keping. 2000. Rights politics and public politics — an analysis of contemporary western political philosophy. Beijing: Social Science Literature Publishing House.

Zhan, Xueyong, and Shuiyan Tang. 2013. Political opportunities, resource constraints and policy advocacy of environmental NGOs in China. Public Administration 91 (2): 381-399.

Zhang, Qingcai. 2013. The evolution and trend of environmental law in contemporary China: analysis based on international environmental security. Beijing: Guangming Daily Press.

Zheng, Yan, and Li Meng. 2014. To promote state governance system and state governance capacity modernization. Journal of Jilin University Social Science 2: 5-13.

Zheng Zeng. 2014. The relationships between civil society organizations and government in environmental governance. Xiamen University School of public affairs Master's degree thesis.

Zhou, Wei. 2006. The difficulties and countermeasures of NGOs in policy participation. Xiangtan University School of Management Master's degree thesis.

Zhu, Jiangang. 2011. Struggle by custom: urban collective action strategy-the case of Guangzhou South Park owners of rights movement. Society 3: 24-41.

Submit your manuscript to a SpringerOpen ${ }^{\circ}$ journal and benefit from:

- Convenient online submission

- Rigorous peer review

- Open access: articles freely available online

- High visibility within the field

- Retaining the copyright to your article

Submit your next manuscript at $>$ springeropen.com 